American Journal of Pharmaceutical Education 2019; 83 (3) Article 6581.

\title{
RESEARCH
}

\section{A Didactic Community Pharmacy Course to Improve Pharmacy Students' Clinical Skills and Business Management Knowledge}

\author{
Katura C. Bullock, PharmD, ${ }^{a}$ Sheritta Horne, PharmD ${ }^{b}$ \\ ${ }^{a}$ University of North Texas System College of Pharmacy, Fort Worth, Texas \\ b Tom Thumb Pharmacy, Dallas, Texas \\ Submitted June 13, 2017; accepted August 23, 2017; published April 2019.
}

Objective. To create, implement and evaluate a Doctor of Pharmacy (PharmD) course on clinical services in community pharmacy settings.

Methods. A 2-credit hour elective course was offered to second- and third-year pharmacy (P2 and P3) students. The course was developed using integrated course design principles. Community pharmacists were featured prominently in the course. Student performance on quizzes was evaluated and compared between groups (2014 and 2015 cohort). A survey with a pretest posttest design was used to assess students' self-rated knowledge and self-efficacy.

Results. Twenty students enrolled in the elective course and 18 students completed the pre/post survey. There was no difference in performance scores on each of the three quizzes between students in the 2014 and 2015 courses. There was a significant increase seen for knowledge of the majority of course competencies. Students indicated improvement in their confidence to perform a variety of clinical services after course completion.

Conclusion. Participation in this elective course allowed students to improve their knowledge of community pharmacy practice competencies and increased their ability to deliver clinical services in community pharmacy settings.

Keywords: community pharmacy, clinical services, business management, elective, didactic

\section{INTRODUCTION}

In the United States, pharmacy services have historically been delivered at the community level. This practice continues to today. In $2014,44 \%$ of all actively practicing pharmacists worked in an independent, chain, mass merchandiser, or supermarket pharmacy. ${ }^{1}$ A hallmark of community pharmacy is that it is a point of contact for the profession to the public. According to the National Association of Chain Drug Stores (NACDS), most Americans (92\%) live within five miles of a community pharmacy. ${ }^{2}$ These pharmacies serve as a trusted, accessible source of health care that provides effective communication with patients. Patients report high levels of satisfaction with community pharmacies, citing benefits such as strong pharmacist-patient relationships and provision of quality services. ${ }^{3,4}$ Community pharmacists have expanded their roles beyond dispensing by providing a growing number of value-added, patient-focused services. In 2004 , only $13 \%$ of community pharmacies

Corresponding Author: Katura C. Bullock, University of North Texas System College of Pharmacy, RES 411E, 3500 Camp Bowie Blvd., Fort Worth, TX 76107. Tel: 817-7352907. E-mail: katura.bullock@unthsc.edu provided medication therapy management (MTM), 15\% offered immunizations, and $7 \%$ offered health screenings. Over the course of 10 years, these numbers have more than tripled with $60 \%$ of pharmacies providing MTM, $53 \%$ providing immunizations, and $48 \%$ offering health screenings. ${ }^{1}$

Student pharmacists are expecting to incorporate this clinical emphasis into their training and in their future practice. In a survey conducted by Maynard and colleagues, fourth-year pharmacy students agreed or strongly agreed that opportunities exist to provide clinical services in a community pharmacy $(87 \%)$ and that it is important to offer these services to patients (95\%). Most students reported they were interested in $(65 \%$ strongly agree) and planned to (53\% strongly agree) provide clinical services in their future practice; however, most did not feel prepared to deliver these services (ready to: $36 \%$ strongly agree) ${ }^{5}$

For pharmacy students, community practice is most likely addressed in the context of experiential education. Starting with Standards 2007, introductory pharmacy practice experiences (IPPE) explicitly require exposure to community pharmacy settings. ${ }^{6}$ Community pharmacy 


\section{American Journal of Pharmaceutical Education 2019; 83 (3) Article 6581.}

is also included as a required advanced pharmacy practice experience (APPE) in Standards 2016. ${ }^{7}$ These required APPEs are intended to prepare practice-ready graduates. Due to the detailed guidelines regarding community pharmacy practice in IPPE and APPE applications, there is a robust body of literature regarding the development, delivery, and assessment of experiential rotations for pharmacy students in community settings. ${ }^{8-11}$

Community IPPE and APPE within the curriculum provide students an opportunity to observe, interact with, and apply skills in community pharmacy practice. For these experiences to be productive for the students and the practice site, students should also have exposure to relevant foundational knowledge. In 2012, ACPE created a taskforce composed of members from NACDS and the National Community Pharmacist Association (NCPA), to develop competencies required for an entry-level community pharmacist. ${ }^{12}$ These professional organizations identified competencies in areas including pharmacistdelivered patient care, public health, communication, dispensing systems management, business management, pharmacy law, and leadership. These competencies have since been incorporated into ACPE Standards 2016 (Guidance Documents) further highlighting the significant role of community pharmacy practice. ${ }^{13}$ These competencies also include recommended performance objectives that should reflect both didactic and experiential education and apply to all colleges and schools of pharmacy.

The noted resources for community pharmacy experiential training stand in stark contrast to the limited literature on didactic coursework related to community pharmacy practice. There have been a few studies that primarily focused on a single patient-care skill commonly used in community pharmacy. Kuhn and colleagues delivered an elective course on MTM services in the community setting. Students who participated in the course indicated that they acquired skills necessary to provide MTM. ${ }^{14}$ Pharmacy-based health screenings related to cancer, cardiovascular disease, osteoporosis, and diabetes were the focus of a course described by Raney. ${ }^{15}$ In this elective course, students performed well on projects and reported a high level of preparedness and interest in establishing pharmacy-based health screening services.

Despite a high level of student interest in clinical services in community pharmacy, published research on this topic remains relatively narrow in scope. To address this curricular gap, we developed an elective course focused on the non-dispensing tasks of community pharmacists. This paper describes the design of a PharmD elective on community pharmacy practice that was created to address the unmet need of didactic coursework related to this major topic area in professional pharmacy education. We evaluated students' performance by measuring quiz scores. We also assessed students' self-rated knowledge, skills, and satisfaction with the course through a survey. The overall goal of the elective course was to promote the development of essential clinical and business management skills needed to provide patientfocused care in community pharmacy settings.

\section{METHODS}

The Clinical Community Pharmacist was offered as a 15-week, two credit hour elective course to pharmacy students in the P2 or P3 years at the University of North Texas System College of Pharmacy (UNT SCP). Related course work at UNT SCP includes the Pharmacy Practice series, which introduces the history of pharmacy and communication principles in the first year of the curriculum. P1 students practice and demonstrate several patient care skills in Pharmacy Practice Skills Lab, such as patient assessment, use of point-of-care testing devices, and medication counseling. Students are also required to complete an 80-hour IPPE in a community pharmacy setting following their first year. The course was developed and coordinated by a pharmacist faculty member with previous community pharmacy practice experience.

In designing this course, the course coordinator sought input from the Center for Innovative Learning (CIL). The CIL is a resource available at University of North Texas Health Science Center (UNTHSC) that offers expertise in instructional design, online curriculum design and development, technical support and best practices in teaching and learning as well as support for educational technology and assessment services. The CIL instructional designers advocate the use of an integrated course design process. Integrated course design is an approach that guides instructors through a series of intentional steps to achieve a high level of significant learning among students. ${ }^{16,17}$

The learning outcomes for the elective course were derived directly from the competencies identified by NACDS/NCPA. ${ }^{12}$ These course learning outcomes served as the foundation for the selection of course materials, reading assignments, evaluation methods, etc. The competencies of NACDS and NCPA are comprehensive and inclusive of all aspects of community pharmacy practice. As the focus of the elective course was direct patient care services, additional expanded learning goals were developed to measure the skills necessary to deliver these services. The expanded pharmacist-delivered patient care goals were also based on the NACDS/NCPA recommendations.

Assessment tools were selected to ensure that students achieved the learning outcomes of the course. After consultation and review by CIL staff, analytic rubrics 


\section{American Journal of Pharmaceutical Education 2019; 83 (3) Article 6581.}

were designed for each of the required, graded activities in the elective course. Rubrics for each assignment were posted to the course learning management system at the beginning of the course to be readily available to students. Throughout the semester, there were also three quizzes each administered in a multiple-choice format. These quizzes were not comprehensive.

The course featured a variety of guest lecturers who were actively practicing community pharmacy and providing clinical services. This teaching strategy demonstrated to students that principles discussed in the course were readily being applied in the local pharmacy community. In addition to using assigned readings, community pharmacist speakers were encouraged to provide firsthand accounts and personal experience to discuss information to students. In this way, the class sessions were relevant, relatable and interactive for students. Each guest lecturer wrote assessment questions that were used on quizzes, which allowed for better integration of their material into the course. These items were peer-reviewed by the course coordinator and mapped to course learning outcomes.

The course coordinator recorded several lectures that were made available to students for viewing on the UNT SCP learning management system. Students were given approximately one week to view the recorded lecture and then respond to a prompt. The prompts required each student to synthesize, explain, and/or apply the material that had been presented in the recorded lecture. These asynchronous recorded lectures were used sporadically throughout the course. A few traditional didactic lectures, 2 to 3 during the course, were also delivered.

Topics covered in the course were selected based on course learning outcomes as identified by NACDS/ NCPA. Additional input on course content was solicited from published surveys of community pharmacy residency program sites. ${ }^{18}$ These were referenced to provide students with a comprehensive profile of patient care services that are typically provided in community pharmacy settings. The course schedule is displayed in Table 1.

\section{Assignments}

Behavior change was a significant focus of the course since community pharmacists are frequently asked to modify a patient's behavior to improve their health. The concept of behavior change was introduced in the course with a didactic lecture on the Transtheoretical Model. For the Behavior Change assignment, each student completed a brief health assessment that addressed specific health behaviors and risks. Lifestyle habits such

Table 1. Course Topics and Corresponding Learning Items in Clinical Community Pharmacy Elective

\begin{tabular}{|c|c|c|}
\hline Week & Topic $^{a}$ & Assessment/Activity \\
\hline \multirow[t]{2}{*}{1} & Course Introduction and Activities & \\
\hline & Overview of Patient Care Services & \\
\hline 2 & Transtheoretical Model of Behavior Change & \\
\hline 3 & Legal and Regulatory Implications ${ }^{\mathrm{a}}$ & \\
\hline \multirow[t]{2}{*}{4} & Operations \& Workflow ${ }^{\text {b }}$ & \\
\hline & Chronic Disease Management $^{\mathrm{a}}$ & \\
\hline 5 & & $\begin{array}{l}\text { Elevator Pitch Presentations } \\
\text { Quiz \#1 }\end{array}$ \\
\hline 6 & Point-of-Care Testing $^{a}$ & \\
\hline 7 & Immunizations $^{\mathrm{a}}$ & \\
\hline 8 & Revenue and Billing ${ }^{\mathrm{a}}$ & Behavior Change Assessment \\
\hline \multirow[t]{2}{*}{9} & Marketing and Promotion ${ }^{\mathrm{b}}$ & \\
\hline & Health and Wellness Screenings ${ }^{\mathrm{a}}$ & \\
\hline 10 & Open Session & Quiz \#2 \\
\hline 11 & Medication Therapy Management ${ }^{\mathrm{a}}$ & \\
\hline 12 & Medication Errors ${ }^{\mathrm{a}}$ & \\
\hline \multirow[t]{2}{*}{13} & Adherence/Compliance ${ }^{\mathrm{b}}$ & \\
\hline & Specialty Pharmacy ${ }^{\mathrm{a}}$ & \\
\hline \multirow[t]{2}{*}{14} & Group Discussion & Behavior Change Plan \\
\hline & & Quiz \#3 \\
\hline \multirow[t]{2}{*}{15} & & Verbal Presentation \\
\hline & & Written Proposal \\
\hline
\end{tabular}

${ }^{a}$ Topic covered by community pharmacist guest lecturer

${ }^{\mathrm{b}}$ Recorded lecture 


\section{American Journal of Pharmaceutical Education 2019; 83 (3) Article 6581.}

as nutrition, physical activity, weight control, sleep hygiene, tobacco use, alcohol consumption, stress management, and medication compliance were included on the assessment. Students identified any barriers to behavior change and personal health goals. They also provided their readiness to change related to specific lifestyle habits.

Following completion, each student received an anonymous, de-identified health assessment of a fellow classmate. The course coordinator was responsible for exchanging health assessments among students. Based upon the anonymous health assessment received, students had to assume the role of a pharmacist and prepare a behavior change action plan for a "patient." The action plan was required to address areas for improvement, provide goals and set follow-up. A debriefing was held to discuss the assignment and action plans.

For the Community Pharmacy Business Practice Plan, students could choose their groupmates (2-3 people per group). Each group was given a scenario where they were the pharmacist-in-charge of a community pharmacy who was interested in starting a new clinical service. The groups were tasked with presenting the patient care service proposal to the pharmacy owners. Groups could choose which clinical service they would like to implement. Each group received identical, detailed information about the hypothetical community pharmacy, including the patient population demographics, location, total sales and revenue, personnel, etc.

The Business Practice Plan was assessed in three parts:

Elevator Pitch. A student from each group was required to deliver an elevator pitch for 30 seconds to 2 minutes to get a follow-up conversation with the pharmacy owners regarding their patient care service proposal. The elevator pitch was delivered during the initial part of the course to ensure groups had selected a clinical service and had begun working on the Business Practice Plan. All students were responsible for answering questions related to their proposed service following the elevator pitch.

Verbal Presentation. All group members were required to participate in the verbal presentation of their business plan. This was a 15-minute presentation with time allotted for questions. The presentation was made to a panel of faculty members and/or community pharmacists who portrayed the role of pharmacy owners. The intention of the verbal presentation was to convince the owners to integrate the new clinical service into the pharmacy environment.

Written Proposal. Each group submitted a written business plan. This written proposal required students to provide a detailed description of their patient care service. Many of the topics presented throughout the course were addressed in the proposal, including marketing and promotion, revenue and billing, and personnel and physical requirements such as operations and workflow. Students were also expected to anticipate the patient care, clinical, and economic outcome measures that would be affected because of their new service.

Students were allotted dedicated class time to work on the Business Practice Plan during the Open Class Session. This class occurred approximately at the midpoint of the course. The course coordinator spent time with each group to monitor progress on their group project since it contained multiple components and was summative in nature.

Students were assessed in the elective course on a pass or no pass basis. A passing grade in the course was comprised of earning a $70 \%$ or better average on quizzes, completing the Behavior Change Assignment, responding to prompts following recorded lectures, and earning a satisfactory evaluation of their group Business Practice Plan from the pharmacy panel.

A survey was used with a pretest and posttest design to assess students' knowledge of the course outcomes, self-efficacy, and satisfaction. The 5-part survey was administered electronically through the learning management system used at UNT SCP. Survey items were developed by the course coordinator and reviewed by CIL staff. Part 1 was composed of seven items asking students to rate their knowledge of statements that corresponded to the learning outcomes of the course. A 5-point Likert scale $(1=$ poor to $5=$ excellent $)$ was used. Part 2 measured students' confidence in their ability to perform patient care skills with 17 items that were identified as expanded learning goals. A 5-point Likert scale $(1=$ not at all confident to $5=$ very confident) was used for these evaluations. The pretest component of the survey included Parts 1 and 2. Part 3 involved students reflecting on several course features. For each course feature, students determined their level of satisfaction and if the feature facilitated the development of patient care skills. Part 4 asked specific questions relating to the content and delivery of the elective course. A 5-point Likert scale $(1=$ strongly disagree to $5=$ strongly agree $)$ was used. The final section of the survey included open-ended questions for feedback. Students were asked to identify what they most enjoyed, least enjoyed, and suggest changes. Based on the survey question, students' responses were considered either positive, negative, or constructive and then coded for themes. Parts 1-5 of the survey were also administered at the end of the course. The survey was linked to the student's UNT HSC profile to verify student 


\section{American Journal of Pharmaceutical Education 2019; 83 (3) Article 6581.}

participation but results were de-identified prior to analysis. No incentives were provided, and participation was voluntary.

Descriptive statistics were used to evaluate the mean scores on all quizzes administered in the elective course. Performance on quizzes were compared between years and analyzed using a two-tailed Independent Samples $t$ test. Survey responses were analyzed using the Wilcoxon signed-rank test. For all statistical tests, alpha was set at .05. SPSS 23.0 (IBM, Armonk, NY) was used to conduct all the analyses presented. Open comments from the survey were coded for themes and qualitatively evaluated. Based on survey prompts, open-ended question responses were considered positive, negative, or constructive. The Institutional Review Board at UNTHSC approved this project as an exempt study.

\section{RESULTS}

Twenty P2 students ( 13 male and 7 female) enrolled in the elective course. There were 12 students during the fall 2014 semester and eight students in the fall 2015 course.

The performance on course quizzes is shown in Table 2. The mean (SD) grade for quizzes 1, 2, and 3 was 75.4 (13.2), 80.2 (9.3), and 79.8 (10.8), respectively. There was no significant difference in quiz performance between students in the 2014 and 2015 courses. All students successfully completed each of the required course assignments and received a passing grade at the completion of the course.

Eighteen of the 20 students completed both the preand post-test portions of the survey for a response rate of $90 \%$. All 18 survey responses were included in the analysis. Comparing student measures before and after participation in the course, the elective course was associated with an increase in perceived knowledge of community pharmacy competencies (Table 3). When asked to rate their knowledge of the course learning outcomes based on the NACDS/NCPA competencies, student ratings were significantly higher for pharmacist-delivered patient care $(p=.001)$, public health $(p=.001)$, communication skills $(p=.001)$, leadership abilities $(p=.016)$, and legal considerations $(p=.013)$. There was no significant change

Table 2. Student Performance on Quizzes in Clinical Community Pharmacy Elective Course ${ }^{\mathrm{a}}$

\begin{tabular}{llcc}
\hline & $\begin{array}{c}\mathbf{2 0 1 4} \\
(\mathbf{n = 1 2}) \\
\text { M (SD) }\end{array}$ & $\begin{array}{c}\mathbf{2 0 1 5} \\
(\mathbf{n = 8}) \\
\mathbf{M}(\mathbf{S D})\end{array}$ & $\boldsymbol{p}$ value \\
\hline Quiz \#1 & $72.8(14.1)$ & $79.4(11.5)$ & .28 \\
Quiz \#2 & $82.8(8.7)$ & $76.3(9.2)$ & .13 \\
Quiz \#3 & $80.0(12.7)$ & $79.4(7.8)$ & .90 \\
\hline
\end{tabular}

in knowledge for course learning outcomes related to dispensing systems management $(p=.052)$ or business management $(p=.13)$.

For the expanded learning goals related to pharmacist-delivered patient care, students indicated improved self-efficacy in 15 out of 17 skills (Table 4). Students reported no significant change in confidence for delivery of MTM $(p=.92)$ or making appropriate recommendations or referrals $(p=.083)$.

In Part 3 of the survey instrument, students were asked several questions on course features to evaluate if the course features facilitated development of patient care skills and their level of satisfaction. Responses in Table 5 show that unique course features were received positively by students. A strongly agree or agree response for the facilitation scale and a very satisfied or somewhat satisfied response for the satisfaction scale were considered a positive response. All students rated positively the community pharmacist participation in the course for both facilitation and satisfaction. The Behavior Change Action Plans were rated positively by $94 \%$ of students for both facilitation of patient care skills and satisfaction. For the Business Practice Plan, 83\% of students answered positively for facilitation of patient care skills with $89 \%$ being satisfied with its use in the course. Part 4 of the survey included questions assessing course content and delivery. For all statements, the mean score was higher than 4 and at least $85 \%$ of students responded positively (considered agree or strongly agree responses) as seen in Table 6.

Of a total of 78 completed responses about the course, general positive feedback was an element of 35 comments, negative elements were included in 20 comments, and constructive feedback was included in 20 comments based on prompts. Students were asked to describe their favorite aspect of the course. Almost half of the responses stated the community pharmacist guest lecturers. Also, frequently mentioned were the Community Pharmacy Business Practice Plan and the small class size. When asked to identify their least favorite aspect of the course, students listed the class schedule and the health screening activity. An additional question asked students to provide any changes for the course. Responses were variable but suggestions for improvement included clarification of the Business Practice Plan, increased visibility of assignments/rubrics on the learning management system, and peer evaluations for group projects.

\section{DISCUSSION}

This elective course was designed to teach students the clinical services frequently offered in community pharmacy settings and to develop their business management skills in delivering such a service. Student performance data and 


\section{American Journal of Pharmaceutical Education 2019; 83 (3) Article 6581.}

Table 3. Evaluation of Course Outcomes on Survey in Clinical Community Pharmacy Elective Course ${ }^{\mathrm{a}}$

\begin{tabular}{|c|c|c|c|c|}
\hline & $\begin{array}{c}\text { Median } \\
\text { Pre-course }\end{array}$ & $\begin{array}{c}\text { Median } \\
\text { Post-course }\end{array}$ & $\mathbf{Z}$ & $p$ value $^{\mathrm{b}}$ \\
\hline Please rate your knowledge of the following: & & & & \\
\hline $\begin{array}{l}\text { Clinical skills necessary to provide direct patient care services in a } \\
\text { community pharmacy setting. }\end{array}$ & 3.0 & 4.0 & -3.34 & .001 \\
\hline Role of the community pharmacist in public health activities. & 3.0 & 4.0 & -3.35 & .001 \\
\hline Oral and written communication skills used in community pharmacy practice. & 3.0 & 5.0 & -3.21 & .001 \\
\hline Responsibility of the community pharmacist in dispensing activities. & 4.0 & 4.0 & -1.94 & .052 \\
\hline Business management skills necessary to lead community pharmacy practice. & 4.0 & 5.0 & -1.51 & .13 \\
\hline Self-direction and lifelong learning behaviors. & 3.0 & 4.0 & -2.41 & .016 \\
\hline $\begin{array}{l}\text { Federal and state laws and regulations that impact community pharmacy } \\
\text { practice. }\end{array}$ & 4.0 & 4.0 & -2.49 & .013 \\
\hline
\end{tabular}

survey results indicate the course was successful in achieving the desired goals while improving student perceptions of their ability to perform patient care skills

A structured method known as the integrated course design process was used to develop this course. Using integrated course design, the first component is to develop significant learning outcomes. The NACDS/NCPA competencies served as learning outcomes for this elective and described the cognitive skills that students were expected to achieve upon completion of the course. The second component is to select an informative learning assessment. A variety of assessment tools were created,

Table 4. Evaluation of Learning Goals on Survey in Clinical Community Pharmacy Elective Course ${ }^{\mathrm{a}}$

\begin{tabular}{|c|c|c|c|c|}
\hline & $\begin{array}{c}\text { Median } \\
\text { Pre-course }\end{array}$ & $\begin{array}{c}\text { Median } \\
\text { Post-course }\end{array}$ & $\mathbf{Z}$ & $p$ value $^{b}$ \\
\hline \multicolumn{5}{|l|}{ Please rate your level of confidence in your ability to: } \\
\hline Demonstrate strong clinical skills. & 3.0 & 4.0 & -2.35 & .019 \\
\hline Provide direct patient care services. & 3.0 & 4.0 & -2.72 & .007 \\
\hline Deliver Medication Therapy Management. & 3.0 & 4.0 & -1.69 & .92 \\
\hline Support and assist patient behavior change. & 3.0 & 4.5 & -3.21 & .001 \\
\hline Proactively identify and resolve patient-specific barriers to medication adherence. & 3.0 & 4.5 & -3.38 & .001 \\
\hline Complete physical assessments. & 3.0 & 4.0 & -3.26 & .001 \\
\hline Make appropriate recommendations or referrals. & 4.0 & 4.0 & -1.73 & .083 \\
\hline $\begin{array}{l}\text { Describe personalized medicine and apply an individual patient's genetic } \\
\text { profile to the selection and modification of a medication regimen. }\end{array}$ & 3.0 & 4.0 & -2.97 & .003 \\
\hline Demonstrate knowledge of specialty pharmaceuticals. & 2.0 & 4.0 & -2.79 & .005 \\
\hline Support patient adherence and administration of specialty pharmaceuticals. & 2.5 & 3.5 & -2.96 & .003 \\
\hline Describe and apply clinical practice guidelines to patient care. & 3.0 & 4.0 & -2.90 & .004 \\
\hline Facilitate patient self-administration of medications and disease monitoring. & 3.0 & 4.0 & -3.22 & .001 \\
\hline $\begin{array}{l}\text { Demonstrate knowledge of appropriate administration technique for dosage } \\
\text { forms commonly dispensed in community pharmacy. }\end{array}$ & 4.0 & 4.0 & -2.50 & .013 \\
\hline Proactively assess and resolve issues related to medication safety. & 4.0 & 4.0 & -2.31 & .021 \\
\hline Demonstrate knowledge of common drugs and diseases requiring monitoring. & 3.0 & 4.0 & -3.10 & .002 \\
\hline Describe collaborative drug therapy management. & 3.0 & 4.0 & -2.85 & .004 \\
\hline $\begin{array}{l}\text { Proactively perform counseling and medication education that complies with } \\
\text { OBRA-90. }\end{array}$ & 3.0 & 4.0 & -3.01 & .003 \\
\hline
\end{tabular}

${ }^{a}$ Learning goals are adapted from the NACDS Foundation-NCPA-ACPE Joint Task Force. Entry-level competencies needed for community pharmacy practice ${ }^{12}$

${ }^{\mathrm{b}}$ Wilcoxon signed-rank test significant difference between pre-course and post-course responses

$1=$ Not at all Confident, $2=$ Not So Confident, $3=$ Somewhat Confident, $4=$ Confident, $5=$ Very Confident 


\section{American Journal of Pharmaceutical Education 2019; 83 (3) Article 6581.}

Table 5. Student Perception of Clinical Community Pharmacy Elective Course Features

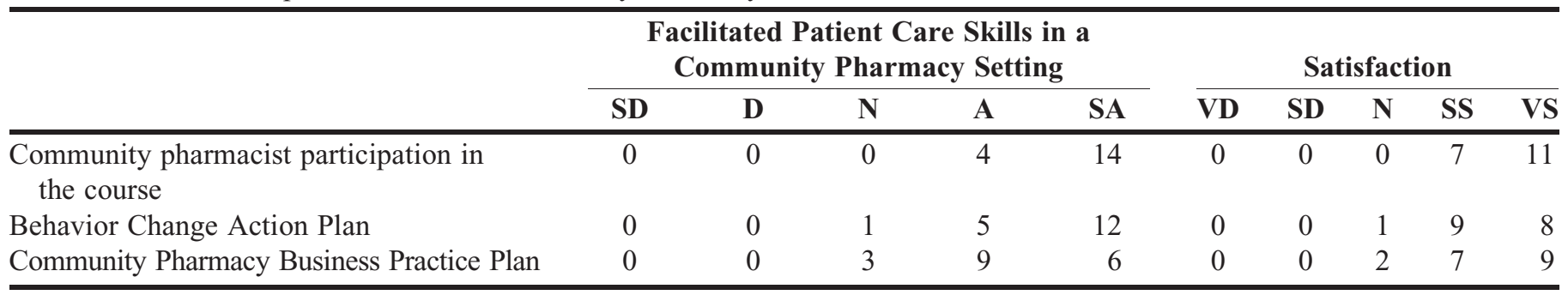

$\mathrm{SD}=$ Strongly Disagree, $\mathrm{D}=$ Disagree, $\mathrm{N}=$ Neutral, $\mathrm{A}=$ Agree, $\mathrm{SA}=$ Strongly Agree

$\mathrm{VD}=$ Very Dissatisfied, $\mathrm{SD}=$ Somewhat Dissatisfied, $\mathrm{N}=$ Neutral, $\mathrm{SD}=$ Somewhat Satisfied, $\mathrm{VS}=$ Very Satisfied

from quizzes to multiple rubrics. Each assessment measure was directly related to the outcomes of the course and the learning objectives of individual activities. The final component is the implementation of engaging learning activities. Course activities included community pharmacist guest lecturers, behavior change action plans, and the Business Practice Plan. Use of the integrated course design in course development allowed for creation of active, relevant, quality instruction in alignment with course outcomes while maximizing resources.

Students demonstrated competency as measured by the three quizzes in the course. Scores on the quizzes were relatively consistent between each quiz and among the 2014 and 2015 courses. Course goals were achieved as students' self-rated knowledge of the majority of course learning outcomes improved significantly during the elective course. No significant improvement was seen regarding the pharmacist's responsibility in dispensing activities as this was rated highly on the pre-course survey and was likely not as emphasized as other topics by guest lecturers. Although no statistically significant improvement was seen, post-course business management results were more positive than pre-course results. In addition, business and finance was mentioned by multiple students as their favorite aspect of the elective on the post-course survey.

Student perception of their ability to deliver clinical services in a community pharmacy setting also significantly improved. The elective course in this study encompassed the full breadth of clinical opportunities typically offered at community pharmacy sites. The topics and active-learning activities used in the course were chosen after consideration of the entry-level competencies identified by professional organizations as well as references from community pharmacy residencies. The improvements in patient care preparedness that students noted were likely attributable to the comprehensive nature of the material that was discussed during the elective.

Students found many of the course features to be beneficial. Engagement of the community pharmacist guest lecturers has been key to the development and delivery of the elective. Community pharmacist lecturers delivered over half of the course material. Due to the integral involvement of outside speakers, the course coordinator took specific actions to ensure that community pharmacists were viewed as essential, connected components of the course. Each lecturer received course information prior to his or her presentation and follow-up after. Students were given the lecturer's professional bio and contact information to allow for questions. Students appreciated the participation of content experts with firsthand experience in providing the clinical services or addressing the management topics that were covered in the course. The guest lecturers were well received by the students as noted on the post-course survey with both qualitative responses and comments on the open-ended responses. Informal feedback from the community pharmacists has also been positive. The community pharmacists, most of whom are preceptors, appreciated interacting with the students in a didactic setting. All have returned to participate in the course for multiple years.

Students felt that the Behavior Change Action Plan was a valuable activity. Previous studies have shown that

Table 6. Pharmacy Students Responses to Survey Questions on Elective Course Content and Delivery

\begin{tabular}{ll}
\hline Questions & Mean Response $^{\mathbf{a}^{2}}$ \\
\hline The open class sessions helped my group prepare for the Community Pharmacy Business Practice Plan. & 4.2 \\
The amount of material covered in this course was reasonable for the amount of credit. & 4.3 \\
The information covered in this course will be useful in my future pharmacy practice. & 4.6 \\
The level of difficulty of this course was appropriate for an elective. & 4.3 \\
This course should continue to be offered as an elective to students. & 4.7 \\
\hline
\end{tabular}

${ }^{\mathrm{a}} 1=$ Strongly Disagree, $2=$ Disagree, $3=$ Neutral, $4=$ Agree, $5=$ Strongly Agree 


\section{American Journal of Pharmaceutical Education 2019; 83 (3) Article 6581.}

pharmacists can positively impact patient outcomes by affecting behavior change. ${ }^{19}$ When completing the brief health assessment, students provided thorough responses regarding lifestyle habits. Their ease in responding may have been because the course coordinator assured them that their assessments were exchanged anonymously among classmates.. They were also able to relate this activity to the facilitation of patient care skills as completing an assessment and designing personalized goals that will likely occur in a community pharmacy setting.

Students considered the Community Pharmacy Business Practice Plan as a difficult, yet rewarding component of the course. In the current community pharmacy landscape, patient care services are often a new endeavor that must be proposed and/or supported by individual or groups of pharmacists. This process requires a set of knowledge and skills that is distinct from delivering the service. The rubric for the Business Practice Plan was intentionally designed so that the most topics covered in the course were assessed to ensure students were able to detect relevance. Each group of students was expected to decide which clinical service they wanted to propose. Students created services such as diabetes education classes, comprehensive immunization services, specialty HIV management including point-of-care testing, and "PharmFit" a triad of MTM, nutrition, and exercise support offerings. Students were largely satisfied with the Business Practice Plan but noted some challenges. They had minimal previous knowledge of business or finances, so the financial analysis and revenue/billing items on the rubric were areas of weakness. A guest lecturer who holds dual degrees of PharmD and MBA addressed these areas but additional class time may need to be allotted in the future.

A continuous improvement approach has been adopted for the course. For instance, during the Fall 2014 cohort, students were asked to complete a health screening activity in which they partnered with a local community pharmacy to participate in a health screening event. Feedback from the students indicated this activity was difficult to schedule and duplicative of events in their community pharmacy IPPE. Since it was not an engaging learning activity, it was removed from the schedule for the Fall 2015 semester.

In addition, future courses will feature a rubric for the postings in response to the recorded sessions to enhance the dialogue among students. The intent is to increase utilization of instructional technology available through the learning management system, such as discussion board features. Students commented that the class time was viewed negatively. The elective course was primarily offered on Tuesdays at 8 a.m. While the overall course calendar is not under the purview of the course director, awareness of this limitation leads to consideration of a hybrid course delivery. Maximizing the use of recorded sessions and associated discussion board activities can reduce the need for didactic lectures. The involvement of community pharmacists can be maintained as students recognized the value of the guest lecturers who presented in class sessions.

Another improvement would be to give students additional guidance related to the written proposal required for the Business Practice Plan. Each group of students received identical background information about a hypothetical community pharmacy to develop a clinical service proposal. The course director did not provide many details related to the submission to generate originality and creativity. The student groups were able to be creative, but many were also anxious about technical issues such as page length, spacing, tables, etc. This was an unanticipated concern of the students that will be addressed in future course offerings. It is the objective of the course coordinator for students to focus on the content of the proposal as opposed to the format.

One limitation of this study was the small number of students who participated in the elective course and the small number of students who completed the survey. Despite the small sample size, improvement was noted in almost all course outcomes. Additionally, students indicated an improvement in perception of their ability to perform most clinical skills in a community pharmacy setting. Students who enrolled in the course felt that the small class size was a benefit of the elective. With a small class size, students had more opportunities to ask questions and engage in discussion. The course is heavily reliant on community pharmacist guest lecturers. Guest lecturers were initially identified through contacts of the course coordinator and the UNTSCP Office of Experiential Education. Feedback regarding the overall course and individual performance has been important to keep community pharmacists engaged and willing to continue to participate in the course.

\section{CONCLUSION}

The Clinical Community Pharmacist elective course exposed students to the knowledge and skills necessary to provide direct patient care services in a community pharmacy setting. Community pharmacists were highly involved in the course to provide insight and expertise. The course addressed a wide range of clinical activities commonly performed in community pharmacy settings. Students reported that course activities were valuable to improve patient interaction, clinical skill development, 


\section{American Journal of Pharmaceutical Education 2019; 83 (3) Article 6581.}

and business management awareness. As community pharmacy represents the largest sector of the workforce, colleges and schools of pharmacy should be mindful of the opportunities for exposure to community pharmacy practice, both didactic and experiential, within their curriculum. It is critical that students are prepared to provide clinical services to patients now and in the future to allow for development and expansion of such services.

\section{REFERENCES}

1. National Association of Change Drug Stores Foundation. 2014 National pharmacist workforce survey. 2010-2011 chain pharmacy industry profile. Alexandria, VA: NACDS.

2. Kelling SE. Exploring accessibility of community pharmacy services. Innov Pharm. 2015;6(3):210.

3. Malewski DF, Ream A, Gaither CA. Patient satisfaction with community pharmacy: comparing urban and suburban chainpharmacy populations. Res Social Adm Pharm. 2015;11(1):121128.

4. J.D. Power. 2016 U.S. Pharmacy Study. J.D. Power. http:// www.jdpower.com/press-releases/jd-power-2016-us-pharmacystudy. Published August 26, 2016. Accessed June 1, 2017. 5. Maynard RA, Wagner ME, Winkler SR, Montuoro JL. Assessment of student pharmacists perceptions on participating in clinical services in the community pharmacy setting. Curr Pharm Teach Learn. 2011;3(2):123-136.

6. Accreditation Council for Pharmacy Education. Accreditation standards and guidelines for the professional program in pharmacy leading to the doctor of pharmacy degree ("Standards 2007 v2.0"). Published February 2011. https://www.acpe-accredit.org/pdf/ FinalS2007Guidelines2.0.pdf. Accessed June 1, 2017.

7. Accreditation Council for Pharmacy Education. Accreditation standards and key elements for the professional program in pharmacy leading to the doctor of pharmacy degree ("Standards 2016"). Published February 2015. https://www.acpe-accredit.org/pdf/ Standards2016FINAL.pdf. Accessed June 1, 2017.

8. Calomo JM. Teaching management in a community pharmacy. Am J Pharm Educ. 2006;70(2):Article 41.
9. Kassam R, Kwong M. An enhanced community advanced pharmacy practice experience model to improve patient care. Am J Pharm Educ. 2009;73(2):Article 25.

10. Agness CF, Huynh D, Brandt N. An introductory pharmacy practice experience based on a medication therapy management service model. Am J Pharm Educ. 2011;75(5):Article 82.

11. Nuffer W, Gilliam E, Thompson M, Vande Griend J. Establishment and implementation of a required medication therapy management advanced pharmacy practice experience. Am J Pharm Educ. 2017;81(2):Article 36.

12. National Association of Chain Drug Stores. National Community Pharmacists Association, Accreditation Council for Pharmacy Education Task Force. Entry-level competencies needed for community pharmacy practice. https://www.acpe-accredit.org/pdf/ NACDSFoundation-NCPA-ACPETaskForce2012.pdf. Published 2012. Accessed January 21, 2017

13. Accreditation Council for Pharmacy Education. Guidance for the accreditation standards and key elements for the professional program in pharmacy leading to the doctor of pharmacy degree ("Guidance for Standards 2016"). Published February 2015. https:// www.acpe-accredit.org/pdf/GuidanceforStandards2016FINAL.pdf. Accessed June 1, 2017.

14. Kuhn C, Powell PH, Sterrett JJ. Elective course on medication therapy management services. Am J Pharm Educ. 2010;74(3): Article 40 .

15. Raney EC. An elective course on pharmacy-based health screenings. Am J Pharm Educ. 2013;77(6):Article 131.

16. Fink LD. Planning your course: a decision guide. In: Creating Significant Learning Experiences: An Integrated Approach to Designing College Courses. 2nd ed. San Francisco, CA: Jossey-Bass; 2013:293-302.

17. Fink LD. A Self-Directed Guide to Designing Courses for Significant Learning. http:/cte.virginia.edu/wp-content/uploads/ 2013/08/Fink_Designing_Courses_2004.pdf. Accessed June 6, 2017. 18. Schommer JC, Owen JA, Scime GM, Millonig MK. Patient care services provided at primary community pharmacy residency sites. J Am Pharm Assoc. 2013;53(2):e125-e131.

19. Lenz TL, Skradski J, Skrabal MZ, Ferguson L, Monaghan MS. A lifestyle medicine clinic in a community pharmacy setting. Innov Pharm. 2010;1(1):3. 